УДК 615.322:582.998.16].074.015

\title{
ФИТОХИМИЧЕСКОЕ И ФАРМАКОЛОГИЧЕСКОЕ ИЗУЧЕНИЕ КОРНЕЙ ПОДСОЛНЕЧНИКА ОДНОЛЕТНЕГО
}

\author{
(ㄱ) И.В. Пиукова", Д.А. Коновалов, В.А. Карпенко, Л.В. Лигай, С.А. Кулешова \\ Пятигорский медико-фармацевтический институт - \\ фрилиал Волгоградского государственного медицинского университета, \\ пр. Калинина, 11, Пятигорск, 357532 (Россия), e-mail: daironas@mail.ru
}

\begin{abstract}
Приведены сведения об изучении химического состава корней подсолнечника однолетнего (Helianthus annuus L.), культивируемого в Ставропольском крае, и исследовании фармакологической активности его водных извлечений. Установлено, что отвар корней подсолнечника однолетнего может применяться для лечения мочекаменной болезни, а также подагры и других болезней обмена и является практически нетоксичным.

Ключевые слова: подсолнечник однолетний, Helianthus annuиs L., полисахариды, инулин, биологически активные соединения.
\end{abstract}

\section{Введение}

Подсолнечник однолетний (Helianthus annuиs L.) - травянистый однолетник из семейства астровых (Asteraceae). Это одна из ведущих масличных культур, традиционно выращиваемая в Ставропольском крае. Кроме того, подсолнечник однолетний известен как растение, широко используемое в народной медицине. В лечебных целях применяют подсолнечное масло, язычковые и краевые цветки, корни, реже листья растения.

Цветки (язычковые и краевые) Helianthus annuus L. в виде водных извлечений применяют при малярии, спазме бронхов, желудочно-кишечных и почечных коликах в качестве спазмолитического, мочегонного средства, а также при желтухе, заболеваниях сердца, невралгии, ревматизме, радикулите [1].

Согласно литературным данным и собственным исследованиям в цветках Helianthus annuus L. coдержатся флавоноиды (кверцетин, антоцианин), кумарины (скополетин, умбеллиферон), фенолкарбоновые кислоты (кофейная, хлорогеновая), холин, бетаин, горечи [2].

В листьях Helianthus annuus L. содержатся каротин (до 11 мг/\%), каучук, сапонины (эхиноцистовая

Пиукова Ирина Васильевна - старший преподаватель кафедры фармакогнозии, кандидат фармацевтических наук, e-mail: daironas@mail.ru Коновалов Дмитрий Алексеевич - заведующий кафедрой фармакогнозии, доктор фармацевтических наук, профессор Карпенко Валентина Анатольевна - доцент кафедры фармацевтической и токсикологической химии, кандидат фармацевтических наук, Лигай Лилия Вениаминовна - преподаватель кафедры органической химии, кандидат фармацевтических наук

Кулешова Светлана Анатольевна - доцент кафедры фармакологии с курсом клинической фармакологии, кандидат фармацевтических наук кислота), смолистые вещества, холин, фенольные соединения и органические кислоты (янтарная, фумаровая, лимонная и др). В народной медицине настойку листьев растения рекомендуют при отсутствии аппетита, лихорадке, невралгии, особенно простудного характера. Установлена их противовоспалительная активность [3, 4].

В семенах подсолнечника обнаружены жирное масло (до 55\%), белок (24-26\%), углеводы (24-27\%), фитин (около 2\%), дубильные вещества $(1,5 \%)$, каротиноиды, фосфолипиды, органические кислоты (лимонная, винная). В оболочках семян найдены некоторые энзимы. Получаемое из семян подсолнечное масло применяют внутрь при атеросклерозе в качестве

\footnotetext{
* Автор, с которым следует вести переписку.
} 
лечебного и профилактического средства и используют наружно для лечения ожогов, ран, трещин на кожном покрове. Масло применяют внутрь в качестве желчегонного и слабительного средства [1, 2]. Подсолнечное масло широко используют как основу для приготовления масляных экстрактов, пластырей и мазей.

К настоящему времени данные о химическом составе корней Helianthus annuus L. немногочисленны. Химический состав изучен недостаточно, в частности полисахаридный комплекс. Чай из корней подсолнечника в народной медицине используется для выведения из организма большого количества солей, в том числе при мочекаменной болезни.

Цель данной работы - изучение химического состава корней подсолнечника однолетнего и фармакологической активности водного извлечения на модели мочекаменной болезни у лабораторных животных.

\section{Экспериментальная часть}

Объектом работы служили высушенные измельченные корни культивируемого подсолнечника однолетнего, заготовленные осенью в Ставропольском крае в 2011-2012 гг. Измельченное сырье представляло собой кусочки корней различной формы и диаметра, серовато-бурого цвета, горьковатого вкуса со слабым своеобразным запахом.

Для изучения полисахаридного комплекса проводили последовательное фракционное выделение из корней подсолнечника однолетнего водорастворимых полисахаридов (ВРПС), пектиновых веществ (ПВ), гемицеллюлозы А и Б (ГЦА и ГЦБ) по методике Н.К. Кочеткова [5].

Определение количественного содержания полисахаридного комплекса осуществляли гравиметрическим методом [5].

Для определения моносахаридного состава каждой выделенной фракции проводили кислотный гидролиз 2 н кислотой серной в течение 8 ч. Идентификацию проводили хроматографически в присутствии РСО моносахаров в системе БУВ $(4: 1: 5)$. Результаты качественного и количественного составов сахаров представлены в таблице 1 .

Особый интерес в работе для нас представляло изучение инулина. Идентификацию инулина проводили по фруктозе, образующейся после его гидролиза, так как специфических реакций на инулин не найдено:

1) реакция Селиванова (нагревание с резорцином в разбавленной хлористоводородной кислоте) вишнево-красное окрашивание.

2) с реактивом Молиша (20\% спиртовый раствор $\alpha$-нафтола и кислота серная концентрированная) фиолетово-розовое окрашивание. При замене $\alpha$-нафтола резорцином или тимолом образовывалось оранжево-красное окрашивание.

Кроме того, для подтверждения наличия инулина проводили качественный анализ по методике, предложенной Д.А. Шматковым, К.В. Беляковым, Д.М. Поповым [6]. Водное извлечение наносили на хроматографическую пластинку «Силуфол», которую помещали в камеру с 90\% этанолом и хроматографировали восходящим способом. Хроматограмму последовательно обрабатывали $20 \%$ спиртовым раствором тимола и разведенной серной кислотой. Пластинку подсушивали на воздухе и нагревали в сушильном шкафу при температуре $80-85^{\circ} \mathrm{C}$ в течение 5 мин. На хроматограмме появлялось пятно малиново-красного цвета с $\mathrm{R}_{\mathrm{f}}=0,79$.

Количественное определение инулина в корнях подсолнечника проводили с помощью УФспектроскопии. Методика основана на измерении оптической плотности продуктов взаимодействия фруктозы, образовавшейся после расщепления инулина, с резорцином в кислой среде.

Измеряли оптическую плотность водного извлечения с добавлением 5\% раствора кислоты хлористоводородной. Под действием хлористоводородной кислоты одна молекула инулина расщепляется на 34 35 молекул фруктозы и одну молекулу глюкозы. В данных условиях во взаимодействие с резорцином вступает только фруктоза. Таким образом, существует прямая зависимость между концентрацией инулина и фруктозы, образующейся в результате гидролиза.

В корнях подсолнечника однолетнего, помимо инулина, содержатся свободные сахара (фруктозиды). Получали два извлечения - водное и спиртовое: в первое переходили инулин и фруктозиды, во второе - только фруктозиды. По разности двух определений рассчитывали содержание инулина.

В корнях подсолнечника однолетнего содержатся и другие полисахариды (инулоиды), имеющие сходное строение, но отличающиеся меньшим количеством остатков фруктозы в молекуле. Содержание суммы инулина и инулоидов обозначено как содержание суммы фруктозанов. 
Таблица 1. Характеристика полисахаридного комплекса корней подсолнечника однолетнего

\begin{tabular}{c|c|c}
\hline Исследуемые фракции & Выход, \% от воздушно-сухого сырья & Обнаруженные моносахариды, $\mathrm{R}_{\mathrm{f}}$ \\
\hline ВРПС & 0,81 & ${\text { Glc } \mathrm{R}_{\mathrm{f}} 0,29}$ \\
ПВ & 2,5 & Glc $\mathrm{R}_{\mathrm{f}} 0,29$ \\
& & $\mathrm{Xyl}_{\mathrm{f}} 0,43$ \\
ГЦ А & 5,31 & Gal UA $\mathrm{R}_{\mathrm{f}} 0,23$ \\
& & Glc $\mathrm{R}_{\mathrm{f}} 0,29$ \\
ГЦ Б & 1,61 & $\mathrm{Xyl}_{\mathrm{f}} 0,43$ \\
& & Glc $_{\mathrm{f}} 0,29$ \\
\hline
\end{tabular}

Определение суммы фруктозидов и фруктозанов. Аналитическую пробу 1,0 г (точная масса) сырья корней подсолнечника однолетнего (измельченного до размера частиц, проходящих сквозь сито с диаметром отверстий 2 мм) помещали в коническую колбу с водой и нагревали на кипящей водяной бане в течение 30 мин. Охлажденное извлечение фильтровали через ватный тампон в мерную колбу вместимостью 200 мл. Экстракцию проводили дважды.

К полученному водному извлечению прибавляли $10 \%$ раствор ацетата свинца, через 10 мин прибавляли 5\% раствор натрия гидрофосфата, доводили объем раствора до метки водой. Фильтровали извлечение через бумажный фильтр, 10 мл фильтрата помещали в мерную колбу вместимостью 100 мл, доводили водой объем раствора до метки и перемешивали (раствор А).

В две мерные колбы вместимостью 25 мл вносили по 5 мл $0,1 \%$ спиртового раствора резорцина. В первую колбу прибавляли 5 мл раствора А (анализируемый образец), во вторую - 5 мл воды (раствор сравнения). Доводили объем растворов в обеих колбах до метки $30 \%$ раствором кислоты хлористоводородной, нагревали на водяной бане $\left(80^{\circ} \mathrm{C}\right)$ в течение 20 мин, охлаждали, доводили объем раствора до метки. Измеряли оптическую плотность анализируемого образца на спектрофотометре при длине волны $480 \pm 2$ нм в кювете с толщиной слоя 10 мм.

Содержание суммы фруктозидов и фруктозанов в пересчете на инулин и абсолютно сухое сырье в процентах $\left(\mathrm{X}_{1}\right)$ рассчитывали по удельному показателю светопоглощения $\left(A_{1 c b}^{1 \%}=498\right)$.

Определение фруктозидов. Аналитическую пробу сырья 1,0 г (точная масса) помещали в коническую колбу, прибавляли 60 мл 95\% этанола и нагревали на кипящей водяной бане с обратным холодильником в течение 30 мин. Спиртовое извлечение фильтровали в мерную колбу. Далее поступали так же, как указано при определении суммы фруктозидов и фруктозанов.

Содержание фруктозидов в пересчете на инулин и абсолютно сухое сырье в процентах $\left(\mathrm{X}_{2}\right)$ рассчитывали также по удельному показателю светопоглощения.

Содержание фруктозанов в пересчете на инулин и абсолютно сухое сырье в процентах $\left(\mathrm{X}_{3}\right)$ вычисляли по разности содержания суммы фруктозидов и фруктозанов $\left(\mathrm{X}_{1}\right)$ и содержания фруктозидов $\left(\mathrm{X}_{2}\right)$.

Результаты количественного определения приведены в таблице 2.

Дубильные вещества определяли в водных извлечениях корней подсолнечника однолетнего с помощью реакций осаждения и окрашивания [7].

Количественное определение дубильных веществ проводили по методике, приведенной в ГФ ХІ [7, 8].

Минеральный состав корней подсолнечника однолетнего определяли спектральным методом на базе испытательной лаборатории при ФГУП «Кавказгеолсъемка» по методике предприятия МП 4-С - полуколичественный метод анализа минерального сырья из кратера угольного электрода на 50 элементов. Полученные данные приведены в таблице 3.

Таблица 2. Результаты количественного определения инулина в корнях подсолнечника однолетнего

\begin{tabular}{c|c|c|c|c}
\hline № & Содержание, $\%$ & $x_{i}-\bar{X}$ & $\left(x_{i}-\bar{X}\right)^{2}$ & Метрологические характеристики \\
\hline 1 & 6,05 & 0,06 & 0,0036 & $\bar{X}=5,99$ \\
2 & 5,89 & $-0,10$ & 0,0100 & $\mathrm{~S}^{2}=0,0161$ \\
3 & 5,83 & $-0,16$ & 0,0256 & $\mathrm{~S}=0,1269$ \\
4 & 5,94 & $-0,05$ & 0,0025 & $\mathrm{~S}_{\mathrm{x}}=0,0518$ \\
5 & 6,17 & 0,18 & 0,0324 & $\Delta X=0,133$ \\
6 & 6,07 & 0,08 & 0,0064 & $\varepsilon, \%=2,2$ \\
\hline
\end{tabular}


Таблица 3. Минеральный состав корней подсолнечника однолетнего

\begin{tabular}{c|c|c|c|c|c}
\hline № & Название элемента & Содержание, \% & № & Название элемента & Содержание, \% \\
\hline 1 & Медь & 0,005 & 11 & Ванадий & 0,005 \\
2 & Цинк & 0,006 & 12 & Хром & 0,006 \\
3 & Барий & 0,06 & 13 & Бор & 0,01 \\
4 & Стронций & 0,06 & 15 & Калий & Натрий \\
5 & Фосфор & 2,0 & 16 & Кальций & 3,0 \\
6 & Литий & 0,003 & 17 & Магний & 10,0 \\
7 & Марганец & 0,06 & 18 & Алюминий & 3,0 \\
8 & Кобальт & 0,0005 & 19 & Кремний & 15,0 \\
9 & Никель & 0,003 & & & \\
10 & Железо & 1,0 &
\end{tabular}

\section{Обсуждение результатов}

В результате проведенных исследований из корней подсолнечника однолетнего, выращенного в Ставропольском крае, выделены полисахариды (общий выход в пределах 10,31+0,20\%). Водорастворимые полисахариды (ВРПС - 0,81\%), представляют собой порошок кремового цвета, сладковатого вкуса, растворимый в воде. Пектиновые вещества (ПВ - 2,5\%) представляют собой волокнистый порошок серого цвета, медленно растворимый в воде. Гемицеллюлозы (ГЦ) А и Б представляют собой после высушивания массу серо-коричневого цвета без запаха, трудно растворимую в воде. Содержание ГЦ А - 5,13\%, ГЦ Б 1,61\%. Методом бумажной хроматографии исследовали компонентный состав полисахаридного комплекса. В качестве «свидетелей» использовались РСО моносахаров.

Содержание инулина в корнях подсолнечника однолетнего составляет от 5,49 до 6,17\%.

Доказано наличие в исследуемом сырье дубильных веществ преимущественно конденсированной

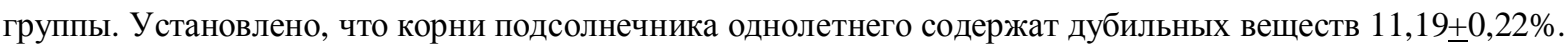

Анализ минерального состава показал, что корни подсолнечника однолетнего содержат значительное количество минеральных элементов в комплексе с другими биологически активными веществами. Установлено присутствие 19 жизненно необходимых элементов в допустимой концентрации. Преобладают макроэлементы: калий, кальций, магний, фосфор. Среди микроэлементов высоким содержанием отличаются барий, марганец, железо, кремний.

Выход экстрактивных веществ, извлекаемых водой очищенной, составил $30,55 \pm 0,41 \%$, при показателях влажности сырья - 2,58+0,35\%, общей золы $-6,50+0,38 \%$ и золы, нерастворимой в $10 \%$-ной хлористоводородной кислоте, $-0,38+0,03 \%$.

Исследование фармакологической активности водного извлечения, полученного из корней подсолнечника однолетнего. Из измельченного сырья, проходящего сквозь сито с отверстиями диаметром 7 мм, готовили отвар (30 г корней подсолнечника однолетнего заливали 150 мл воды и кипятили 10 мин, охлаждали, фильтровали через ватно-марлевый тампон).

До создания модели мочекаменной болезни предварительно собирали мочу лабораторных животных. Анализ мочи интактных животных показал отсутствие кристаллов мочевой кислоты, фосфатов, оксалатов, уратов.

Мочекаменную болезнь моделировали на 12 особях женского пола массой 210-240 г путем введения субтоксических доз растворимого стрептоцида. Водный раствор стрептоцида в дозе, соотнесенной с суточной дозой для человека, вводили перорально в течение 21 дня. Животные получали питье, подкисленное хлористоводородной кислотой.

На 7-й, 14-й и 21-й день животных помещали в «обменные» клетки, собирали мочу и оценивали ее состав $[9,10]$. В собранной моче обнаруживали возрастающую концентрацию фосфатов, уратов, оксалатов, мочевой кислоты, мочекислого аммония. У большинства животных рН мочи была кислой $(2,7-3,5)$.

Высокая концентрация кристаллов солей в моче крыс на 21-й день свидетельствовала о нарушении выделительной функции почек. Кроме солей, в моче некоторых крыс контрольной и опытной групп присутствовали лейкоциты от 8-9 до 18-20 в поле зрения.

Животные меньше двигались, больше лежали, меньше потребляли пищи обычного рациона.

С 22-го дня опыта экспериментальным крысам вводили перорально с помощью зонда отвар корней подсолнечника однолетнего в суточной дозе 25 мл/кг. 
Анализ мочи, сделанный через 14 дней от начала лечения, показал ее щелочность и отсутствие обнаруживаемых ранее кристаллов солей.

В моче крыс контрольной группы (без лечения) на 7-й и 14-й дни по-прежнему обнаруживали высокое содержание уратов, оксалатов, трипельфосфатов, мочевой кислоты, мочекислого аммония (рис.).

Важно отметить, что в моче крыс, получавших отвар корней подсолнечника, в поле зрения микроскопа визуализировали 1-2 лейкоцита или их полное отсутствие. В моче крыс контрольной группы содержание лейкоцитов в поле зрения оставалось высоким (15-20).

Таблица 4. Исследование осадка мочи крыс при введении водного раствора субтоксической дозы стрептоцида

\begin{tabular}{c|c|c|c}
\hline \multirow{2}{*}{ Показатель } & \multicolumn{3}{|c}{ Дни исследования } \\
\cline { 2 - 4 } & 7-й & 14-й & В1-й \\
\hline Количество осадка & Незначительное & Умеренное \\
\hline Состав осадка & Трипельфосфаты & Трипельфосфаты & Трипельфосфаты \\
& & Ураты & Ураты \\
& & Мочекислый аммоний & Мочевая кислота \\
& & & Оксалаты кальция \\
\hline
\end{tabular}

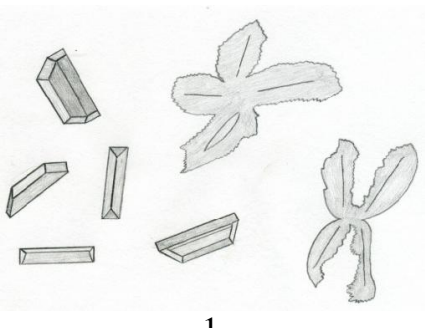

1

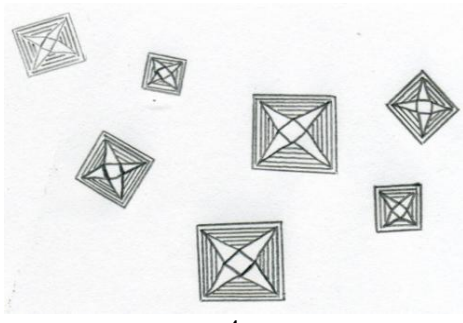

4

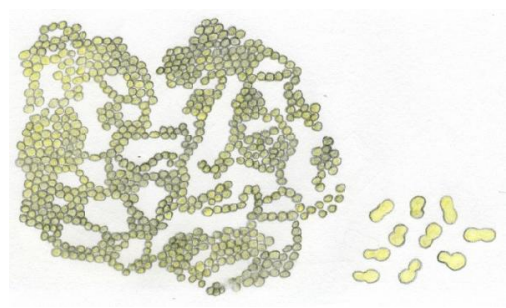

2

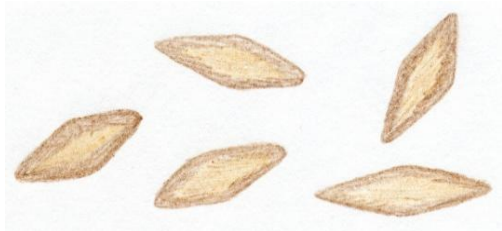

5

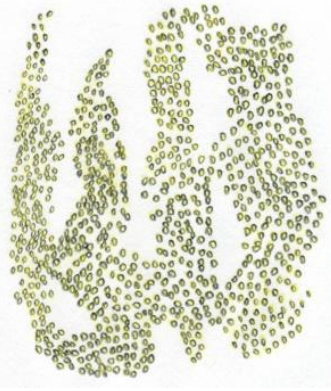

3

Кристаллы, содержащиеся в моче крыс, под микроскопом:

1 - трипельфосфатов; 2 - уратов;

3 - мочекислого аммония;

4 - мочевой кислоты; 5 - оксалата кальция

\section{Bblводы}

1. Проведен фитохимический анализ корней подсолнечника однолетнего, установлено содержание БАС.

2. На крысах линии Wistar путем введения субтоксических доз стрептоцида растворимого создана модель мочекаменной болезни.

3. Установлено, что отвар из корней подсолнечника однолетнего (1 : 5) снижает в моче лабораторных животных с моделью мочекаменной болезни содержание уратов, оксалатов, мочекислого аммония и трипельфосфатов и может применяться для лечения мочекаменной болезни, а также подагры и других нарушений обмена.

4. Корни подсолнечника однолетнего перспективны для использования в качестве лекарственного растительного сырья.

\section{Список литературы}

1. Растительные ресурсы СССР: Цветковые растения, их химический состав, использование. Семейства Asteraceae (Compositae). СПб., 1993. С. 81-83.

2. Бубенчикова В.Н., Дроздова И.Л., Пшукова И.В. и др. Изучение состава фенольных соединений цветков подсолнечника однолетнего // Краеведение в Курском крае: прошлое и современность. Межрегиональные связи : сб. тр. 2 Междунар. науч. краевед. конф. Курск, 2007. Ч. 2. С. 38-41. 
3. Таова М.Р. Исследование противовоспалительной активности извлечений листьев и корней подсолнечника масличного // Научное обозрение. 2010. №1. С. 24-26.

4. Таова М.Р., Коновалов Д.А. Изучение фенольных соединений листьев подсолнечника однолетнего методом высокоэффективной жидкостной хроматографии // Научные ведомости Белгородского государственного университета. Серия: Медицина. Фармация. 2011. №16. Вып. 15. С. 244-245.

5. Кочетков Н.К. Химия биологически активных соединений. М., 1970. 486 с.

6. Шматков Д.А. Определение инулина в корнях лопуха большого // Фармация. 1998. Т. 47, №6. С. 17-20.

7. Химический анализ лекарственных растений / под ред. Н.И. Гринкевич, Л.Н. Сафронович. М., 1983. 176 с.

8. Государственная фармакопея СССР. Вып. 1: Общие методы анализа. 11-е изд., доп. М., 1987. 336 с.

9. Аляев Ю.Г. Изучение мочевых камней методами in vivo и in vitro // Вопросы биологической, медицинской и фармацевтической химии. 2005. №3. С. 31-40.

10. Руководство по экспериментальному доклиническому изучению новых фармакологических веществ / под ред. Р.У. Хабриева. М., 2005. С. 501-514.

Поступило в редакииюю 24 мая 2013 г.

Pshukov I.V., Konovalov D.A., Karpenko V.A., Ligaj L.V., Kuleshova S.A. PHYTOCHEMICAL AND PHARMACOLOGICAL STUDYING OF ROOTS OF COMMON SUNFLOWER

Piatigorsky Medical and Pharmaceutical Institute - a branch of Volgograd State Medical University, Kalinina ave., 11, Piatigorsk, 357532 (Russia),e-mail: daironas@mail.ru

Data on studying of a chemical composition of roots of common sunflower (Helianthus annuus L.) are resulted, cultivated in Stavropol Territory, and research of pharmacological activity of its water extraction. It is established that infusion and broth of roots of common sunflower can be applied to treatment of urolithic illness, and also a gout and other illnesses of an exchange and are almost nontoxical.

Keywords: common sunflower, Helianthus annuus L., polysaccharides, inulin, biologically active compounds.

\section{References}

1. Rastitel'nye resursy SSSR: Tsvetkovye rasteniia, ikh khimicheskii sostav, ispol'zovanie. Semeistva Asteraceae (Compositae). [Plant Resources of the USSR: Flowering plants, their chemical composition and utilization. The family Asteraceae (Compositae)]. St. Petersburg, 1993, pp. 81-83. (in Russ.).

2. Bubenchikova V.N., Drozdova I.L., Pshukova I.V. Kraevedenie v Kurskom krae: proshloe i sovremennost'. Mezhregional'nye sviazi : sb. tr. 2 Mezhdunar. nauch. kraeved. konf. [Local interest in the Kursk region: Past and Present. Interregional relations : Proceedings of the 2 International Scientific Conference]. Kursk, 2007, part. 2, pp. 38-41. (in Russ.).

3. Taova M.R. Nauchnoe obozrenie, 2010, no. 1, pp. 24-26. (in Russ.).

4. Taova M.R., Konovalov D.A. Nauchnye vedomosti Belgorodskogo gosudarstvennogo universiteta. Seriia: Meditsina. Farmatsiia, 2011, no. 16, pp. 244-245. (in Russ.).

5. Kochetkov N.K. Khimiia biologicheski aktivnykh soedinenii. [Chemistry of biologically active compounds]. Moscow, 1970, 486 p. (in Russ.).

6. Shmatkov D.A. Farmatsiia, 1998, vol. 47, no. 6, pp. 17-20. (in Russ.).

7. Khimicheskii analiz lekarstvennykh rastenii. [Chemical analysis of medicinal plants]. Ed. N.I. Grinkevich, L.N. Safronovich. Moscow, 1983, 176 p. (in Russ.).

8. Gosudarstvennaia farmakopeia SSSR. Vyp. 1: Obshchie metody analiza. 11-e izd. [State Pharmacopoeia of the USSR. Issue 1: General methods of analysis. 11th ed.]. Moscow, 1987, 336 p. (in Russ.).

9. Aliaev Iu.G. Voprosy biologicheskoi, meditsinskoi i farmatsevticheskoi khimii, 2005, no.3, pp. 31-40. (in Russ.).

10. Rukovodstvo po eksperimental'nomu doklinicheskomu izucheniiu novykh farmakologicheskikh veshchestv. [Manual on experimental preclinical studies of new pharmacological agents]. Ed. R.U. Khabriev. Moscow, 2005, pp. 501-514. (in Russ.).

\footnotetext{
* Corresponding author.
} 